\title{
Caesarian Section for Placenta Praevia: Does Booking Status Affect Maternofetal Outcome?
}

\author{
Oshodi Yusuf Abisowo*, Akinola Oluwarotimi Ireti, Fabamwo Adetokunbo Olusegun, \\ Olaifa Ibrahim Adeniyi, Oyedele Yekeen Oyedokun \\ Department of Obstetrics and Gynaecology, Lagos State University Teaching Hospital, Ikeja, Nigeria \\ Email: "yusufoshodi@gmail.com
}

Received 4 December 2015; accepted 25 April 2016; published 28 April 2016

Copyright (C) 2016 by authors and Scientific Research Publishing Inc.

This work is licensed under the Creative Commons Attribution International License (CC BY). http://creativecommons.org/licenses/by/4.0/

(c) (i) Open Access

\section{Abstract}

Background: Placenta praevia accounts for significant maternal morbidity and perinatal morbidity and mortality. Despite advances in blood transfusion technique and surgical procedure, abnormal placentation still remains a difficult challenge for obstetricians. Objective: To determine the influence of booking status on the fetal and maternal outcome among parturients with placenta praevia that underwent caesarian delivery. Methodology: This was a comparative and retrospective study between booked and unbooked subjects with significant placenta praevia that were delivered by caesarian section between January $1^{\text {st }} 2004$ and December $31^{\text {st }} 2008$ with respect to maternal and fetal outcome. Result: Out of 14,344 deliveries during study period, 123 cases of placenta praevia that underwent caesarian delivery were identified giving a prevalence rate of $0.86 \% .49$ subjects were booked while 74 were unbooked. There was no statistically significant difference between booked and unbooked cases with respect to risk factors $(30.6 \%$ of booked and $23 \%$ of unbooked), $X^{2}(4)=7.203, P=0.126$ and the mean blood loss at surgery $(870.4 \pm 486.9$ $\mathrm{ml}$ in booked versus $779.7 \pm 380.96 \mathrm{ml}$ in unbooked), $\mathrm{X}^{2}(1)=0.202, \mathrm{P}=0.653$. However, antepartum transfusion $(12.2 \%$ booked versus $34.7 \%$ unbooked) and postpartum transfusion $(51 \%$ booked versus $72 \%$ unbooked) showed statistically significant difference, $X^{2}(1)=9.744, P=0.002$. One maternal death occurred amongst the unbooked cases and none among the booked cases. Statistically significant differences were also noted in the apgar score at 1 minute $X^{2}(3)=15.528, P=$ 0.001 and 5 minutes $X^{2}(3)=12.912, P=0.005$ respectively. More babies died in the unbooked group (19) compared to two (2) in the booked mothers. Conclusion: Unbooked status in placenta previa significantly increases the risk for antepartum and postpartum transfusion, is associated with higher mortality, increased preterm delivery, poorer apgar scores and higher perinatal mortality rate.

\footnotetext{
${ }^{*}$ Corresponding author.
}

How to cite this paper: Abisowo, O.Y., Ireti, A.O., Olusegun, F.A., Adeniyi, O.I. and Oyedokun, O.Y. (2016) Caesarian Section for Placenta Praevia: Does Booking Status Affect Maternofetal Outcome? Open Journal of Obstetrics and Gynecology, 6, 306-312. http://dx.doi.org/10.4236/ojog.2016.65039 


\section{Keywords}

\section{Placenta Praevia, Maternal Outcome, Fetal Outcome, Booking Status, Caesarian Delivery}

\section{Introduction}

Placenta praevia is generally defined as the implantation of the placenta over or near the internal as of the cervix [1]. There are three types - namely total, partial or marginal. It is one of the main causes of vaginal bleeding in the third trimester complicating $0.3 \%$ to $0.6 \%$ of all pregnancies [2]. There is higher incidence of low lying placenta diagnosed sonographically in the second trimester which ranges from $6 \%-46 \%$; however this rate reduces to about $0.5 \%$ at delivery [3] [4].

Placenta praevia accounts for significant maternal morbidity and perinatal morbidity and mortality [5]. Although its aetiology remains speculative, several risk factors associated with this condition include advanced maternal age, multiparity, multiple gestation, smoking during pregnancy, a male fetus, previous history of placenta praevia, previous uterine scar following instrumentations, myomectomy and previous caesarian delivery [6] [7].

Mothers with placenta praevia present with painless vaginal bleeding after fetal viability but before delivery. The bleeding is usually mild and recurrent but sometimes can be massive and life threatening. Severe bleeding in placenta preavia is associated with severe maternal morbidity and sometimes mortality. This is especially so in developing countries where few women attends antenatal care, shortage of blood for transfusion and delay of operative delivery due to logistic problems [8].

Despite advances in blood transfusion technique and surgical procedure, abnormal placentation still remains a difficult challenge for obstetricians. Intrapartum haemorrhage and the need for emergencies caesarian delivery or hysterectomy related to placenta accreta are main causes of maternal and fetal morbidity and mortality [9].

Evidence abounds of unique unquestionable benefit of antenatal care [10]-[12] but it would only be effective in this case if there was routine ultrasound examination on all women who attended to localize the placenta early third trimester. This will identify cases with placenta praevia and their management planned. Though women giving birth at home without antenatal care have suffered severely impaired outcome [13], recent systematic review suggested that women with low risk pregnancies can safely have fewer antenatal care visit [14].

While marginal placenta praevia could be delivered vaginally, caesarian section is reserved for some partial and total placenta praevia including any type with life threatening bleeding [15]. This study is conducted to determine the influence of booking status on the fetal and maternal outcome among parturients with placenta preavia that underwent caesarian delivery in our facility.

\section{Subjects and Method}

This was a retrospective comparative study between booked and unbooked subjects with placenta preavia that were delivered by caesarian section between January $1^{\text {st }} 2004$ and December $31^{\text {st }} 2008$ following ethical clearance by our institution's ethics and research committee. Significant placenta praevia is regarded as any bleeding in diagnosed cases that resulted in haemodynamic instability or bleeding according to clinical estimation that could have resulted in haemodynamics instability if left untreated.

Case records of patients that had placenta praevia delivered by caesarian section were retrieved and categorized according to booking status. Information was obtained on age, parity, booking, status, risk factors like abortion, previous caesarian delivery, mode of delivery and estimated blood loss. Other data extracted include antepartum haemorrhage, post partatum haemorrhage, placenta percreta, hysterectomy, apgar scores at $1^{\text {st }}$ and $5^{\text {th }}$ minute including perinatal outcome and maternal mortality rate.

Data were analysed using the SPSS version 11.0 (Statistical package for social sciences, Inc 2001; Chicago 111). Descriptive statistics (mean, standard deviation) were calculated for continuous variables. Proportions and percentages were calculated for categorical variables. Chi-square (non-parametric test) was appropriately used to examine the statistical significant of the differences between categorical distributions.

P-value less than 0.05 was considered statistically significant and level of confidence interval set at $95 \%$. 


\section{Results}

Out of 14,344 deliveries that took place during the five year study period, 123 cases of placenta previa that underwent caesarian delivery were identified giving a prevalence rate of $0.86 \% .49$ subjects were booked while 74 were unbooked.

Table 1 shows the age distribution and frequency between booked and unbooked cases. The mean age for booked case was $32.6 \pm 4.17$ years while that for the unbooked was $30.92 \pm 4.99$ years. All subject had caesarian delivery with $69.4 \%$ and $89.2 \%$ of booked and unbooked cases having emergency surgery respectively (Table 2).

Review of risk factors (Table 3 ) shows that majority of the subjects had no risk factors while previous instrumentation following termination of pregnancy was found in 30.6\% of booked and 23\% of unbooked patients. The differences between booked and unbooked cases with respect to risk factors was not statistically significant $\mathrm{X} 2(4)=7.203, \mathrm{P}=0.126$.

Table 4 shows that the transfusion pattern amongst the subject $34.7 \%$ of unbooked cases have ante-partum transfusion compared to $12.2 \%$ of booked. Also $74 \%$ of unbooked cases had postpartum transfusion compared to $51 \%$ of booked case. This was found to be statistically significant $X^{2}(1)=9.744, P=0.002$.

Table 5 depicts the estimated blood loss at surgery in both groups. The mean blood loss for booked cases was $870.4 \pm 486.9 \mathrm{mls}$ while that for unbooked cases was $779.7 \pm 380.96 \mathrm{ml}$. This difference was not found to be statistically significant $\mathrm{X}^{2}(1)=0.202, \mathrm{P}=0.653$.

One maternal death was recorded amongst the unbooked cases while no death occurred in the booked cases. This gives maternal mortality rate of 813 per 100,000 live birth but there was no statistically significant difference between booked and unbooked cases with respect to maternal mortality rate $\mathrm{X}^{2}(1)=0.668 \mathrm{P}=1.000$.

The fetal outcome measures were gestational age at delivery, apgar scores @ $1^{\text {st }}$ and $5^{\text {th }}$ minutes and perinatal Mortality rate. The gestational age at delivery showed that only $20.4 \%$ booked cases have preterm delivery compared to $50 \%$ of unbooked cases. This is very significant as reflected in perinatal mortality result. Table 6 shows apgar score at 1st minute between the two groups. A large of proportion babies of booked mothers have better apgar scores at first minute compared to their unbooked counterpart. $\mathrm{X}^{2}(3)=15.528, \mathrm{P}=0.001$. Table 7 represent apgar score distribution at $5^{\text {th }}$ minute. A large population of babies born to unbooked mothers (8.2\%) had moderate asphyxia compared to $2.0 \%$ of babies delivered by booked mothers; this was found to be statistically significant. $\mathrm{X}^{2}(3)=12.912, \mathrm{P}=0.005$.

Table 8 represents perinatal mortality between the 2 groups. There were 2 perinatal deaths amongst booked cases giving case fatality ratio (CFR) of $4.2 \%$ while 19 deaths occurred in unbooked group with case fatality ratio of $25.7 \%$.

\section{Discussion}

Placenta previa may present with life threatening vaginal bleeding that requires immediate caesarian section. In

Table 1. Age distribution amongst booked and unbooked cases.

\begin{tabular}{ccc}
\hline Age & Booked & Unbooked \\
\hline $20-24$ & $1(2 \%)$ & $8(10.8 \%)$ \\
$25-29$ & $9(18.4 \%)$ & $14(18.9 \%)$ \\
$30-34$ & $25(51 \%)$ & $36(48.6 \%)$ \\
$35-39$ & $11(22.4 \%)$ & $14(18.9 \%)$ \\
$\geq 40$ & $3(6.1 \%)$ & $2(2.7 \%)$ \\
Total & 49 & 74 \\
\hline
\end{tabular}

Mean: Booked $32.6 \pm 4.17$ yrs Unbooked $30.92 \pm 4.99$ yrs.

Table 2. Parity distribution.

\begin{tabular}{ccc}
\hline Parity range & Booked & Unbooked \\
\hline $1-3$ & 31 & 42 \\
$4-5$ & 15 & 28 \\
$>5$ & 3 & 4 \\
Total & 49 & 74 \\
\hline
\end{tabular}


Table 3. Risk factors distributions.

\begin{tabular}{ccc}
\hline Factors & Booked & Unbooked \\
\hline Termination of pregnancy & $15(30.6 \%)$ & $17(23.0 \%)$ \\
Previous caesarian section & $8(16.3 \%)$ & $9(12.2 \%)$ \\
Myomectomy & $2(4.1 \%)$ & - \\
Caesarian section and placenta praevia & $1(2.1)$ & - \\
None & $23(46.9 \%)$ & $74(64.8 \%)$ \\
Total & $49(100 \%)$ & $7400)$ \\
\hline
\end{tabular}

$\mathrm{X}^{2}(4)=7.203, \mathrm{P}=0.126$

Table 4. Transfusion pattern.

\begin{tabular}{ccc}
\hline & Booked & Unbooked \\
\hline Antepartum & $6(12.2)$ & $25(34.7)$ \\
Postpartum & $25(51 \%)$ & $54(74 \%)$ \\
\hline
\end{tabular}

$\mathrm{X}^{2}(1)=9.744, \mathrm{P}=0.002, \mathrm{R} \cdot \mathrm{R}=1.5$.

Table 5. Estimated blood loss.

\begin{tabular}{ccc}
\hline Blood loss & Booked & Unbooked \\
\hline$<1000 \mathrm{ml}$ & $36(73.5 \%)$ & $57(77.0 \%)$ \\
$>1000 \mathrm{ml}$ & $13(26.5 \%)$ & $17(23 \%)$ \\
\hline
\end{tabular}

Mean: Booked $=870.4 \pm 486.9 \mathrm{ml} ;$ Unbooked $=779.1 \pm 380.96 \mathrm{ml} ; \mathrm{X}^{2}(1)=0.202 ; \mathrm{P}=0.653$.

Table 6. Apgar score at 1 minute.

\begin{tabular}{ccc}
\hline A.S & Booked & Unbooked \\
\hline Mild Asphyxia & 19 & 17 \\
Moderate Asphyxia & 22 & 20 \\
Severe & 6 & 18 \\
Still Birth & 2 & 19 \\
& 47 & 74
\end{tabular}

$\mathrm{X}^{2}(3)=15.528 ; \mathrm{P}=0.001$.

Table 7.Apgar series@ 5 minutes.

\begin{tabular}{ccc}
\hline A.S & Booked & Unbooked \\
\hline Normal & 12 & 12 \\
Mild & 34 & 34 \\
Moderate & 1 & 6 \\
\hline
\end{tabular}

$\mathrm{X}^{2}(3)=15.528 ; \mathrm{P}=0.001$.

Table 8. Perinatal mortality in each group.

\begin{tabular}{ccc}
\hline & Booked & Unbooked \\
\hline Perinatal Death & 2 & 19
\end{tabular}

Case fatality Ratio: Booked $=2 / 47 \times 100=4.2 \%$; Unbooked $=19 / 74 \times 100=25.7 \%$.

these cases, multiple blood transfusion and prompt surgical intervention may reduce perinatal and maternal mortality [8]. Despite easy accessibility to high quality maternity care services, some group of women chooses not to utilize it. However, the outcome of their pregnancies was poor, although delivery may finally take place in 
the hospital [16].

The prevalence of placenta previa in this study was 0.86 percent which is relatively greater than that reported for earlier studies [1] [2] but lower than 1.2\% among Asians reported by Tai-Ho et al. [7]. However, this does not reflect the true prevalence because minor cases of placenta previa that had vaginal delivery were not included. The mean age of 32.6 years and 30.92 years for booked and unbooked cases respectively is comparable to that of Fredriksen et al. [17]. There was no association between increasing maternal age and development of placenta previa in this study which agrees with findings of Gorodeski et al. [18] and Dola et al. [19]. This is in contrast with the findings of other workers [6] [7].

The distribution of placenta previa along parity range showed that subjects with lower parity (3 or less) comprising 31 booked and 42 unbooked (59\% all together) had placenta previa. This was in contrast with findings of Ananth et al. [23] and Tai-Ho et al. [7] in which placenta previa is associated with high parity. Though majority of the subjects had no risk factors, this may be associated with higher prevalence of placenta previa amongst the low parity group. However, previous uterine scar following termination of pregnancy and caesarian delivery were seen in about half of booked and 35\% of unbooked subjects. Though no statistically significant difference exist between the two groups, Tuzovic et al. did not find increased risk between these factors and placenta previa [20].

Since the tendency of placenta previa to bleed did not significantly correlate with the type, the need for emergency caesarian delivery was associated the presence of ante-partum haemorrhage and increasing number of bleeding episodes [21]. Differences in antepartum transfusion of $34.7 \%$ in unbooked cases compared to $12.2 \%$ of booked cases was significant $(\mathrm{P}=0.002)$. Same also reflected in postpartum transfusion rate of $74 \%$ in unbooked versus 51\% among the booked cases. This agrees with findings of Dola et al. [19]. However no significant difference exist between the mean estimate blood loss of $870.4 \mathrm{ml}$ in booked and 779.7 in unbooked cases respectively. These values of estimated blood loss were lower than that reported by Fredriksen et al [17].

Three subjects each had hysterectomy in both the booked and unbooked cases giving an incidence of $4.87 \%$. This is higher than that reported by Tuzovic et al. [20]. One maternal death occurred in the unbooked subgroup while there was none in the booked patients giving rate of $0.008 \%$ which is lower than that quoted by Iyasu et al. [22].

While advances in obstetrics and neonatal care significantly reduced perinatal mortality associated with placenta previa, preterm delivery still remains a great problem [2] [23]. 20.4\% of booked and $50 \%$ of unbooked cases had preterm deliveries respectively. The apgar scores evaluation of both groups at the one minute revealed better score among the booked than unbooked cases (Table 5) $\mathrm{P}=0.001$. Same findings also reflected in the 5 minutes apgar scores with $8.1 \%$ and $2 \%$ of babies born to unbooked and booked cases respectively having moderate birth asphyxia (Table 6) $\mathrm{P}=0.005$. The overall perinatal death was two among the booked cases compared to nineteen in the unbooked cases giving case fatality ratio of $4.2 \%$ for booked and $25.7 \%$ for unbooked cases. This was closely related to prematurity and poor apgar scores at fifth minutes having corrected for major congenital malformations which were absent in babies delivered to both group.

Gorodeski and co workers found out that perinatal death is largely associated with marginal placenta previa delivered by vaginal route but in today's condition, most of pregnancies complicated by placenta previa are delivered by caesarian section which significantly reduces perinatal mortality [24]. As a result, immediate delivery at 36 weeks gestation was advocated in cases of placenta previa to optimize the maternal and neonatal outcome [25].

Adequate and careful counseling of women with identifiable risk factors is necessary as soon as pregnancy is confirmed. This is especially important in non-compliant women with possible poor antenatal care. Careful monitoring of these high risk pregnancies is of utmost important with respect to ultrasonographic examination with exact placenta localization during second trimester of pregnancy [26].

\section{Conclusion}

In conclusion, unbooked status in placenta previa was identified as a higher risk subgroup with designated poorer maternal and fetal outcome. Unbooked status significantly increased the risk for antepartum and postpartum transfusion, is associated with higher mortality, increased preterm delivery, poorer apgar scores and high perinatal mortality rate. Early booking in pregnancy affords early recognition and monitoring of placenta previa which could minimize the possibility of poorer outcome in sudden massive vaginal bleeding.

\section{References}

[1] Cunningham, F.C., Grant, N.F., Loveno, K.I., Gilstrap III, L.C., Nanth, J.C. and Wenstrom, K.D. (2001) Obstetrics 
Heamorrhage in: Williams Obsterics $21^{\text {st }}$ Edition. Mc Graw-Hill Company Inc.

[2] Crane, J.M., Van den Hof, M.C., Dodds, L., Amson, B.A. and Liston, R. (2000) Maternal Complications with Placenta Previa. American Journal of Perinatology, 17, 101-105. http://dx.doi.org/10.1055/s-2000-9269

[3] Dashe, J.S., McIntire, D.D., Ramus, R.M., Santos-Ramus, R. and Twickler, D.M. (2002) Persistence of Placenta Previa According to Gestational Age at Ultrasound Detection. Obstetrics \& Gynecology, 99, 692-697. http://dx.doi.org/10.1097/00006250-200205000-00005

[4] Mustafa, S.A., Brizot, M.C., Carvalho, M.H., Wanatabe, L., Kahhale, S. and Zugaib, M. (2002) Transvaginal Ultrasound in Predicting Placenta Previa at Delivery: A Longitudinal Study. Ultrasound in Obstetrics \& Gynecology, 20, 356-359. http://dx.doi.org/10.1046/j.1469-0705.2002.00814.x

[5] Ananth, C.V., Smith, J.C. and Vintzeleos, A.M. (2003) The Effect of Placenta Previa on Neonatal Mortality: A Population Based Study in the United States;1989 through 1997. American Journal of Obstetrics \& Gynecology, 188, 12991304. http://dx.doi.org/10.1067/mob.2003.76

[6] Gilliam, M.L., Mellisa, L.G., Kristi, S., Rosenberg, D., Handler, A. and Davis, P. (2001) Increased Risk of Placenta Previa Associated with Prior Caesarian Delivery. Obstetrics \& Gynecology, 94, S63.

[7] Hung, T.-H., Hsieh, C.C., Hsu, J.J., Chiu, T.H., Lo, L.N. and Hsieh, T.T. (2007) Risk Factors for Placenta Previa in an Asian Population. International Journal of Gynecology \& Obstetrics, 97, 26-30. http://dx.doi.org/10.1016/j.ijgo.2006.12.006

[8] Kiondo, P., Wandabwa, J. and Doyle, P. (2008) Risk Factors for Placenta Praevia Presenting with Severe Vaginal Bleeding in Mulago Hospital, Kampala, Uganda. African Health Sciences, 18, 44-49.

[9] Placenta Previa and Placenta Previa Accreta: Diagnosis and Management. Royal College of Obstetrics and Gynaecologists Guideline No. 15.

[10] Kunzel, W. and Misselwitz, B. (2003) Unexpected Fetal Death during Pregnancy-A Problem of Unrecognized Fetal Disorders during Antenatal Care? European Journal of Obstetrics \& Gynecology and Reproductive Biology, S86-S92.

[11] National Centre for Women's and Children's Health (2003) Antenatal Care: Routine Care for Healthy Pregnant Women. Clinical Guideline First, RCOG Press, London.

[12] Villar, J. and Khan-Neclofur, D. (2002) Pattern of Routine Antenatal Care for Low Risk Pregnancy. Cochrane Database of Systematic Reviews, No. 2, CD000934.

[13] Kaunitz, A.M., Spence, C., Danielson, T.S., Rochat, R.W. and Grimes, D.A. (1984) Perinatal and Maternal Mortality in a Religious Group Avoiding Obstetrics Care. American Journal of Obstetrics \& Gynecology, 150, 826-831. http://dx.doi.org/10.1016/0002-9378(84)90457-5

[14] Carolli, G., Villar, J., Piaggio, G., Khan-Nelofur, D., Gulmezoghi, M., Megford, M., et al. (2001) WHO Antenatal Trial Research Group. WHO Systematic Review of Randomized Controlled Trials of Routine Antenatal Care. Lancet, 357, 1565-1570. http://dx.doi.org/10.1016/S0140-6736(00)04723-1

[15] Eniola, A.O., Bako, A.U. and Selo-Ojeme, D.O. (2002) Risk Factors for Placenta Previa in Southwestern Nigeria. East African Medical Journal, 79, 535-538. http://dx.doi.org/10.4314/eamj.v79i10.8816

[16] Bhide, A., Prefumo, F., Moore, J., Hollis, B. and Thilaganathan, B. (2003) Placenta Edge to Internal os Distance in the Late Third Trimester and Mode of Delivery in Placenta Previa. BJOG: An International Journal of Obstetrics \& Gynaecology, 110, 860-864. http://dx.doi.org/10.1111/j.1471-0528.2003.02491.x

[17] Raatikanen, H., Heiskanen, N. and Hnionen, S. (2007) Under Attending Free Antenatal Care Is Associated with Adverse Pregnancy Outcome. BMC Public Health, 7, 268. http://dx.doi.org/10.1186/1471-2458-7-268

[18] Frederiksen, M.C., Glassenberg, R. and Sticka, C.S. (1999) Placenta Previa: A 22-Year Analysis. American Journal of Obstetrics \& Gynecology, 180, 1432-1437. http://dx.doi.org/10.1016/S0002-9378(99)70031-1

[19] Gorodeski, I.G. and Bahari, C.M. (1987) Effect of Placenta Previa upon Maternal and Feto-Neonatal Outcome. Journal of Perinatal Medicine, 15, 169-177. http://dx.doi.org/10.1515/jpme.1987.15.2.169

[20] Dola, C.P., Gante, T.J., Dowling, D.D., Friend, D., Ahdoot, D. and Asrat, T. (2003) Placenta Previa: Does It Type Affect Pregnancy Outcome? American Journal of Perinatology, 20, 353-360. http://dx.doi.org/10.1055/s-2003-45282

[21] Tuzovic, L. (2006) Complete versus Incomplete Placenta Previa and Obstetrics Outcome. International Journal of Gynecology and Obstetrics, 93, 110-117. http://dx.doi.org/10.1016/j.ijgo.2006.02.006

[22] Love, C.D.B. and Wallace, E.M. (1996) Pregnancy Complicated by Placenta Previa: What Management. BJOG: An International Journal of Obstetrics \& Gynaecology, 103, 864-869. http://dx.doi.org/10.1111/j.1471-0528.1996.tb09903.x

[23] Iyasu, S., Saflas, A.K., Rowley, D.L. and Koonin, L.M. (1993) The Epidermiology of Placenta Previa in the United States, 1979 through 1987. American Journal of Obstetrics \& Gynecology, 168, 1424-1429. http://dx.doi.org/10.1016/S0002-9378(11)90776-5 
[24] Ananth, C.V., Demissie, K., Simulian, J.C. and Vintzeleos, A.M. (2001) Relationship among Placenta Previa, Fetal Growth Restriction and Preterm Delivery: A Population Based Study. Obstetrics \& Gynecology, 98, 299-306. http://dx.doi.org/10.1097/00006250-200108000-00021

[25] Tuzovic, L., Djelmis, J. and Marcela, I. (2003) Obstetrics Risk Factors Associated with Placenta Previa Development: Case Control Study. Croatian Medical Journal, 44, 728-733.

[26] Zlatnik, M., Little, S., Kohli, P., Scotland, N., Karmal, A. and Caughey, A. (2006) When Should Women with Placenta Previa Be Delivered? A Decision Analysis. American Journal of Obstetrics \& Gynecology, 195, S27. http://dx.doi.org/10.1016/j.ajog.2006.10.069 